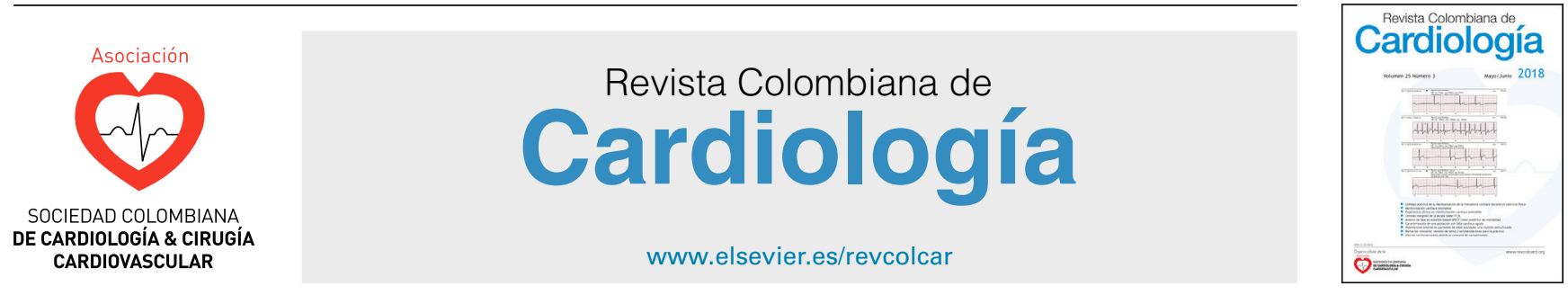

CARDIOLOGÍA DEL ADULTO - REVISIÓN DE TEMAS

\title{
Células madre como alternativa al marcapaso transvenoso
}

\section{Katherine Martínez de Hoyo ${ }^{\mathrm{a}}$, Anamaría Ortega Enciso ${ }^{a}$, Fernán Mendoza Beltrán ${ }^{\mathrm{b}, \mathrm{c}, \mathrm{d}, *}$ y Jorge Reynolds Pombo ${ }^{\mathrm{e}}$}

\author{
a Facultad de Medicina, Universidad El Bosque \\ b Cardiología Clínica y Medicina Interna, Fundación Clínica Shaio, Bogotá, Colombia \\ c Posgrado de Cardiología de Adultos - Universidad El Bosque, Bogotá, Colombia \\ d Grupo de Medicina Cardiovascular y Especialidades de Alta Complejidad - Fundación Clínica Shaio, Bogotá, Colombia \\ e Departamento de Investigación en Electrónica y Nanotecnología, Fundación Clínica Shaio, Bogotá, Colombia
}

Recibido el 3 de julio de 2019; aceptado el 21 de septiembre de 2019

Disponible en Internet el 30 de abril de 2020

\section{PALABRAS CLAVE \\ Marcapasos; \\ Terapia génica; \\ Terapia celular; \\ Células madre; \\ Ingeniería de tejidos}

\begin{abstract}
Resumen
Objetivo: describir el estado del arte del marcapasos biológico y las perspectivas para crear tejido cardíaco de marcapasos utilizando modernas tecnologías genéticas y de ingeniería de tejidos.

Métodos: revisión sistemática de la literatura.

Resultados: los marcapasos se han convertido en el tratamiento primordial para cierto tipo de arritmias o bloqueos avanzados sintomáticos. Somos testigos de mejoras continuas en la tecnología del dispositivo, con avances en el diseño del cable, el tamaño del generador, la longevidad de la batería y los algoritmos de software que se han traducido en dispositivos más pequeños con funcionalidad mejorada. En la actualidad existen muchos sistemas implantables de cardioestimulación capaces de reemplazar la función de los marcapasos fisiológicos (seno y nódulos aurículo-ventriculares) que incluyen los recientemente desarrollados marcapasos secuenciales y autoprogramables. En la última década la investigación ha confirmado que el marcapasos biológico se puede crear mediante la terapia génica y la terapia celular. Hoy existen dos enfoques para construir marcapasos biológicos: uno es para introducir genes de marcapasos en células madre mesenquimales, y el otro es para inducir células madre pluripotentes en las células del nódulo sinoauricular.

Conclusiones: los marcapasos biológicos, actualmente en la etapa preclínica, podrían ser una alternativa a los dispositivos electrónicos para pacientes seleccionados en el futuro.

(C) 2019 Sociedad Colombiana de Cardiología y Cirugía Cardiovascular. Publicado por Elsevier España, S.L.U. Este es un artículo Open Access bajo la licencia CC BY-NC-ND (http:// creativecommons.org/licenses/by-nc-nd/4.0/).
\end{abstract}

\footnotetext{
* Autor para correspondencia.

Correo electrónico: fernan.mendoza@shaio.org (F. Mendoza Beltrán).
} 


\section{KEYWORDS}

Pacemakers;

Gene therapy;

Cell therapy;

Stem cells;

Tissue engineering

\section{Stem cells as an alternative to the transvenous pacemaker}

\begin{abstract}
Objective: To describe the state of the art of biological pacemakers and the perspectives for creating cardiac pacing tissue using modern genetic and tissue engineering technologies.

Methods: A systematic review of the literature.

Results: Pacemakers have become the first line treatment for certain types of arrhythmias and advanced symptomatic blocks. We are witnessing continuous improvements in the technology of the device, with advances in the design of the cable, the size of the generator, the longevity of the battery, as well as the software algorithms that have led to smaller devices with improved functions. There are currently many cardiac stimulation implantable systems capable of replacing the function of physiological pacemakers systems (sinus and atrial-ventricular nodes) that include the recently developed sequential and self-programmable pacemakers. In the last ten years or so, studies have confirmed that biological pacemakers can be created using gene therapy and cell therapy. There are currently to main efforts to construct biological pacemakers. One is to introduce pacemaker genes in mesenchymal stem cells, and the other is to introduce pluripotent stem cells in cells of the sinoatrial node.

Conclusions: Biological pacemakers, currently in the pre-clinical stage, could be an alternative to the electronic devices for selected patients in the future.

(c) 2019 Sociedad Colombiana de Cardiología y Cirugía Cardiovascular. Published by Elsevier España, S.L.U. This is an open access article under the CC BY-NC-ND license (http:// creativecommons.org/licenses/by-nc-nd/4.0/).
\end{abstract}

\section{Introducción}

En el mundo, la principal causa de mortalidad es la enfermedad cardíaca, que ocasiona 17.3 millones de muertes por año en hombres y mujeres, ya sea la forma heredada o adquirida. De ahí nace el interés de los investigadores por mejorar las terapias existentes y buscar un mejor entendimiento, planteando diversos modelos del desarrollo del corazón, con el propósito de identificar nuevos tratamientos farmacológicos y enfoques de bioingeniería basados en células madre para reemplazar el tejido cardíaco dañado ${ }^{1}$. Esta revisión se enfocará en las bradiarritmias [hoy se define bradicardia la existencia de una frecuencia sinusal $<50 \mathrm{lpm}$ y / o una pausa sinusal $>3$ segundos como componentes potenciales de las definiciones de disfunción del nódulo sinusal (DNS) $]^{2}$.

Este hallazgo clínico frecuente, incluye varios trastornos del ritmo, como la disfunción del nódulo sinusal y las alteraciones de la conducción auriculoventricular. Clínicamente puede presentarse de forma asintomática y ser un hallazgo electrocardiográfico incidental (por ejemplo en un examen médico ordinario) o expresarse con una amplia gama de síntomas, como los de insuficiencia cardiaca, presíncope o síncope, del sistema nervioso central o inespecíficos y crónicos, como mareo o fatiga ${ }^{3}$.

La prevalencia de la disfunción del nódulo sinusal está alrededor de 0,03\% y aumenta con la edad. El bloqueo aurículo-ventricular (AV) denota una conducción defectuosa del sistema de conducción AV, puede ser progresivo y en los grados más altos tiene un peor pronóstico. La prevalencia del bloqueo de la conducción AV es cercana al 0,04\% y es más alta en los ancianos y en los hombres ${ }^{4}$.

Por otra parte, se sabe que el proceso de envejecimiento se correlaciona con una pérdida de hasta 20 millones/año de cardiomiocitos (como referencia el ventrículo izquierdo está conformado por 2 a 4 mil millones de cardiomiocitos) y en una situación clínica aguda, como un infarto miocárdico, se pierden millones de células, alcanzando en algunos casos el $25 \%$ de la masa cardíaca total. Si se tiene en cuenta que la regeneración de los cardiomiocitos endógenos es limitada, la compensación de esta pérdida de células se logra mediante la formación de tejido cicatricial fibrótico que altera la contractilidad del corazón. No hace mucho tiempo atrás se pensaba que el corazón era un órgano completamente diferenciado incapaz de regenerarse. No obstante, investigaciones recientes han demostrado que a la edad de 20 años la tasa de renovación de los cardiomiocitos alcanza el $1 \%$ y que a los 70 disminuye hasta el $0,4 \%$ por $a n ̃ 0^{5}$.

\section{Breve historia del marcapasos electrónico}

Los marcapasos electrónicos son la base de la terapia para los ritmos cardíacos lentos (bradicardia) debido a enfermedad del sistema de conducción cardíaco ${ }^{7}$. Albert S. Hyman diseñó el primer marcapasos cardíaco experimental en 1932 y fue allí donde primero introdujo el término "marcapasos artificial" y lo comparó con el marcapasos natural del corazón, el nodo sinoatrial ${ }^{6}$.

Desde el descubrimiento del electrocardiograma por Einthoven en 1902 y el de la estimulación cardiaca por Zoll en $1952^{7}$ se reconocen varios hitos en la historia ${ }^{8,9}$ (tabla 1). Según las estadísticas, en el mundo cada año se implantan 1 millón de nuevos marcapasos, de los cuales una cuarta parte se implantan en los Estados Unidos para bradiarritmias y bloqueos cardíacos ${ }^{10}$. 
Tabla 1 Cambios de paradigma en los marcapasos cardíacos

Cambios históricos de paradigmas en el marcapasos cardiaco

\begin{tabular}{|c|c|c|c|c|c|c|c|}
\hline \multirow[t]{2}{*}{1957} & \multicolumn{3}{|c|}{1958} & \multirow[t]{2}{*}{2015} & \multirow[t]{2}{*}{2016} & \multicolumn{2}{|c|}{ El futuro } \\
\hline & Julio & Octubre & Diciembre & & & Marcapaso sin batería & Marcapasos biológicos \\
\hline \multirow[t]{2}{*}{$\begin{array}{l}\text { Marcapasos } \\
\text { "portátiles" } \\
\text { transistorizados a } \\
\text { pilas (Lillehei / } \\
\text { Bakken) }\end{array}$} & $\begin{array}{l}\text { Marcapasos con } \\
\text { alimentación de } \\
\text { corriente alterna } \\
\text { atados a un cable } \\
\text { de extensión } \\
\text { (Seymour } \\
\text { Furman) }^{35}\end{array}$ & $\begin{array}{l}\text { Primer marcapasos } \\
\text { totalmente } \\
\text { implantable } \\
\text { (Elmqvist / } \\
\text { Senning) en } \\
\text { Suecia }^{12}\end{array}$ & $\begin{array}{l}\text { Marcapasos } \\
\text { artificial externo } \\
\text { con electrodos } \\
\text { internos } \\
\text { epicárdicos } \\
\text { (Ingeniero } \\
\text { Reynolds) en } \\
\text { Colombia }^{13}\end{array}$ & $\begin{array}{l}\text { Marcapasos } \\
\text { implantable: } \\
\text { sistema básico no } \\
\text { evolucionó } \\
\text { significativa- } \\
\text { mente }^{14,15}\end{array}$ & $\begin{array}{l}\text { Marcapasos } \\
\text { inalámbricos: todo } \\
\text { el dispositivo se } \\
\text { coloca en las } \\
\text { cámaras } \\
\text { cardíacas }^{16}\end{array}$ & $\begin{array}{l}\text { Aprovecha los } \\
\text { movimientos } \\
\text { cardiacos para } \\
\text { alimentar los } \\
\text { circuitos del } \\
\text { marcapaso (ej.: el } \\
\text { Micra }^{\circledR} \text { y el } \\
\left.\text { Nanostim }^{\circledR}\right)^{17}\end{array}$ & $\begin{array}{l}\text { 1. Con genes de } \\
\text { marcapasos en } \\
\text { células madre } \\
\text { mesenquimales }\end{array}$ \\
\hline & & & & & & & $\begin{array}{l}\text { 2. Con inducción de } \\
\text { células madre } \\
\text { pluripotentes en las } \\
\text { células del nódulo } \\
\text { sinoauricular }\end{array}$ \\
\hline
\end{tabular}




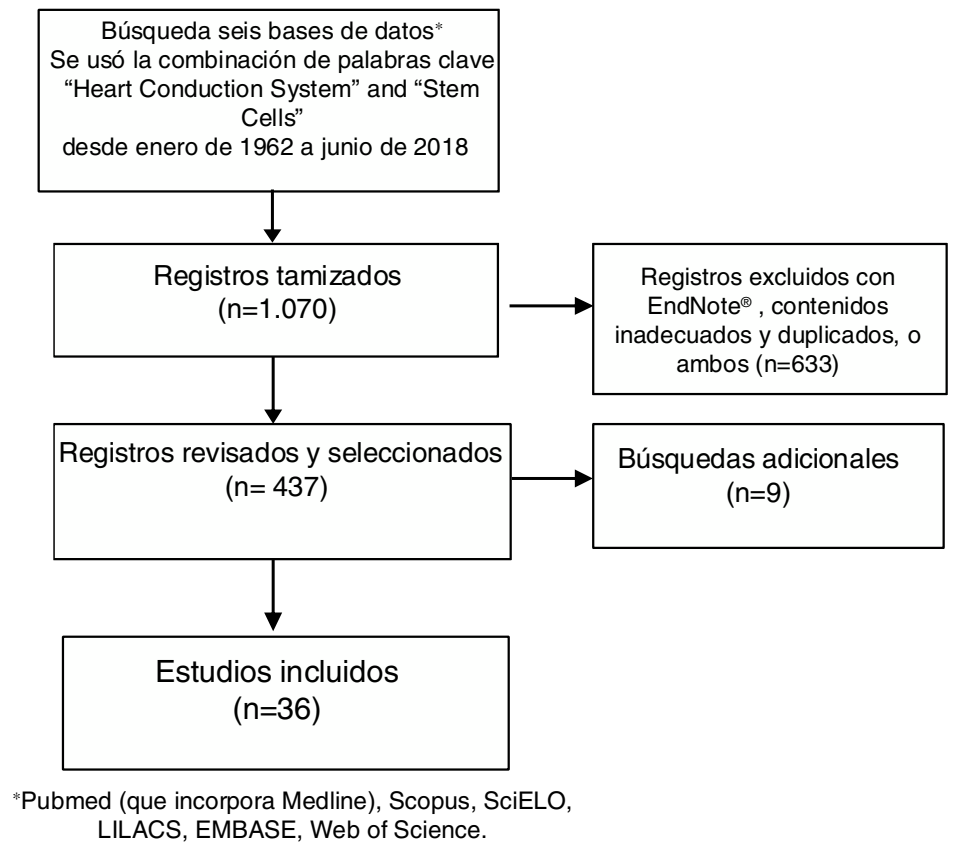

Figura 1 Proceso de selección de estudios.

\section{Problemas del marcapasos artificial}

Las tecnologías de marcapasos electrónico continúan evolucionando; sin embargo, los marcapasos electrónicos tienen limitaciones, como la duración de la batería, la falla del sistema, la incapacidad de proporcionar una respuesta autónoma verdadera y las infecciones relacionadas con los dispositivos ${ }^{11}$.

\section{Métodos}

Búsqueda sistemática de la literatura acerca de las células madre y su uso en el sistema cardionector (fig. 1).

\section{Resultados}

De acuerdo con una búsqueda realizada en mayo de 2018 en GoPubmed el número de publicaciones se ha ido incrementando año tras año (fig. 2) y los países donde más se realizan investigaciones acerca de las células madre y el sistema cardionector, son Estados Unidos, Alemania, China, Israel, Japón, entre otros, y el autor con mayor número de artículos en el tema es Hescheler (fig. 3).

\section{El sistema de conducción cardíaca}

Es una forma amplia de referirse a una colección de diferentes tejidos musculares especializados dentro del corazón, encargados de coordinar la tasa y el ritmo de las contracciones del músculo cardíaco.

El sistema de conducción cardiaca se puede dividir desde el punto de vista fisiológico en: a) nodos de conducción lenta, que incluyen el nodo sinoauricular y el nodo aurículoventricular y b) el sistema de conducción ventricular de conducción rápida, que incluye el haz aurículo-ventricular, las ramas del haz derecho e izquierdo y la red de fibras de Purkinje. El nodo sinoauricular es el marcapasos dominante del corazón y controla su tasa de contracción. Desde el punto de vista anatómico, está ubicado en la unión de la aurícula derecha y la vena cava superior, cerca de la cresta terminal ${ }^{12}$.

Gracias a las investigaciones sobre el desarrollo del sistema de conducción cardiaca, los factores identificados se han implementado para dirigir la diferenciación de células madre hacia los destinos de las células del sistema de conducción cardiaca o para imponer propiedades parecidas a las de los marcapasos en las células cardíacas o no cardíacas $^{12}$.

\section{Nodo sinoauricular adulto}

Es una estructura en forma de coma, de 2 a $3 \mathrm{~cm}$ de longitud, situada en la unión de la vena cava superior y la aurícula derecha, cuya función es generar los impulsos eléctricos cardíacos $^{13}$

Para replicar la funcionalidad del nodo sinoauricular es importante tener en cuenta su heterogeneidad, lo cual convierte en un reto el desarrollo de una población celular homogénea, que, junto con las conexiones al tejido auricular circundante, constituye un punto crítico para el comportamiento sincitial del nodo sinoauricular in vivo. Adicionalmente, hay diferencias en la región nodal en cuanto al tamaño de las células, la densidad de las corrientes iónicas, la expresión de la conexina $(\mathrm{Cx})$ y otros marcadores moleculares que pueden afectar la función ${ }^{14}$. El desarrollo del sistema de conducción cardiaca involucra redes complejas que actúan según su estadio, tejido y dosis-dependencia, y los hallazgos recientes indican que la actividad de estas redes es sensible a variantes genéticas comunes asociadas con arritmias cardíacas ${ }^{15}$. 


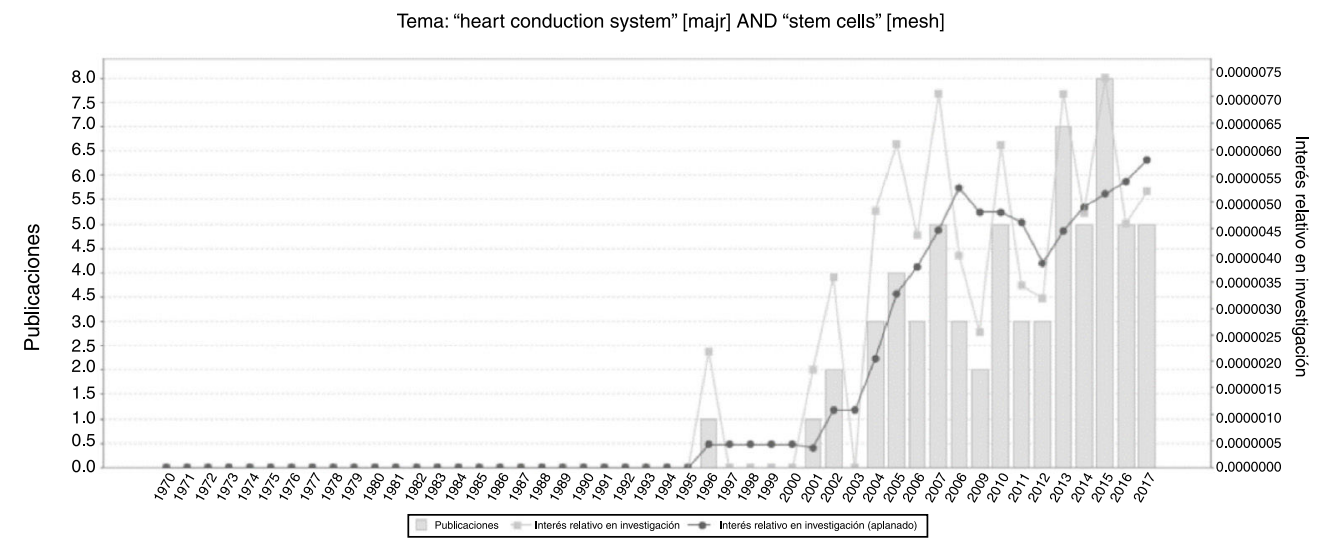

Figura 2 Número de publicaciones desde 1970 a 2017 Tomada de GoPubmed.

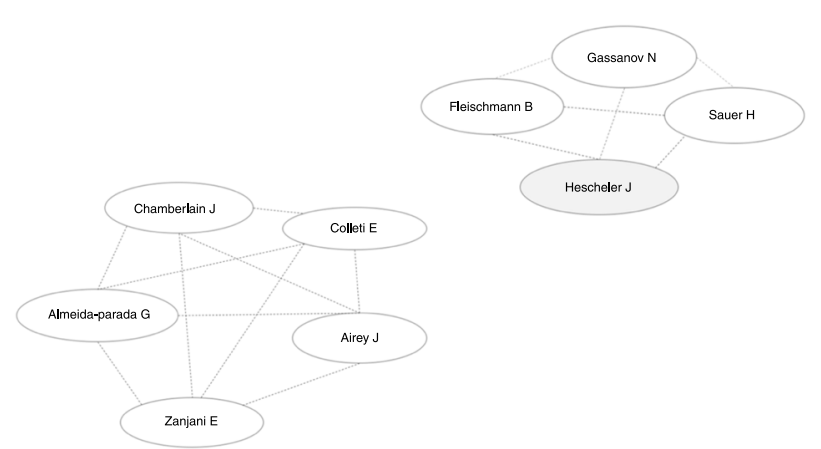

Figura 3 Redes de cooperación células madre / sistema cardionector del mundo

Tomada de GoPubmed.

\section{Origen del desarrollo del nodo sinoauricular}

En 1882 Gaskell propuso su teoría acerca del origen miogénico del latido del corazón y además identificó el nódulo sinusal como la región desde la cual comienzan las contracciones y se propagan al nodo aurículo-ventricular y luego al ventrículo ${ }^{14}$.

Arthur Keith fue el primero en identificar una estructura en el corazón humano, hoy en día conocida como nodo sinoauricular, y cambió el enfoque a este "remanente notable de fibras primitivas que persisten en la unión sinoauricular' ', el cual se demostró corresponde a la ubicación de la excitación cardíaca inicial.

Una perspectiva integral de las células que conforman el sistema cardionector desde su origen embrionario brinda mayor claridad de aspectos importantes empleados en la medicina regenerativa utilizada en la práctica clínica, que constituye abordajes terapéuticos para el manejo de enfermedades como las arritmias cardiacas ${ }^{16}$.

El nodo sinoauricular contiene aproximadamente 10.000 células marcapaso especializadas y se requirieron varias décadas de investigación básica en los mecanismos electrofisiológicos implicados en la automaticidad de las células marcapaso, hecho que finalmente trajo como resultado la identificación y clonación de las estructuras moleculares de las corrientes iónicas de las células marcapaso críticas. Existe una línea de investigación en curso cuyo objetivo es transformar las áreas normalmente inactivas del corazón en marcapasos biológicos basados en que se cuenta con la capacidad de introducir material genético exógeno en células humanas in vitro e in vivo ${ }^{13}$.

Cada latido del corazón es el resultado del impulso eléctrico generado por un estímulo de las células marcapaso gracias a que exhiben automaticidad. Los componentes críticos de la maquinaria eléctrica en las células marcapaso incluyen el intercambiador de sodio-calcio, los canales de calcio regulados por voltaje, los canales de iones cíclicos activados por nucleótidos activados por hiperpolarización (por su sigla en inglés "Hcn") y la liberación espontánea de calcio del retículo sarcoplasmático. Los Hcn y otros canales median la respuesta autónoma a través de su sensibilidad a los cambios en el adenosín monofosfato (AMP) cíclico causado por el estímulo vagal y simpático directo. De los canales tipo Hcn, el Hcn4 es el más expresado en las células marcapaso y cuando está mutado produce bradicardia sinusal familiar $^{13}$.

\section{Tipos de marcapasos biológico}

Marcapasos biológico genético: los tres enfoques iniciales consistieron en: sobreexpresión de los receptores ß-adrenérgicos, regulación negativa de la corriente hiperpolarizante externa IK1 y sobreexpresión de la corriente despolarizante interna ${ }^{17}$.

Marcapasos biológico basado en células madre: las estrategias para su construcción involucran la inyección de un grupo de células no excitables que expresan una corriente interna que despolariza las células contiguas a su umbral de potencial de acción o la inyección de un grupo de células excitables con la capacidad de generar potenciales de acción espontáneos. En el primer caso se requieren al menos dos células (donante + huésped) para crear una unidad de estimulación; en este último, las células administradas son los marcapasos biológicos. Ambas estrategias suponen que la integración de las células liberadas se producirá mediante la formación de uniones estrechas entre las propias células del donante y las células diana ${ }^{17}$.

Actualmente, en la medicina regenerativa cardíaca se explotan dos categorías principales de células madre (CM): a) CM adultas multipotentes y b) CM embrionarias 
pluripotentes (CMEP) y CM pluripotentes inducidas (CMPi), en las que se exploran derivados diferenciados para trasplante o las células se diferencian in situ después del trasplante. Como potencial terapéutico, ambos grupos tienen ciertas ventajas y desventajas ${ }^{5}$.

Para la reparación y regeneración del corazón se ha propuesto la terapia con células madre; sin embargo, se desconocen los mecanismos exactos de reparación cardíaca por células trasplantadas. Existen dos hipótesis principales: a) diferenciación cardiomiogénica / vasculogénica directa, y b) estimulación indirecta de la respuesta reparadora a través de efectos paracrinos. Se están evaluando diferentes tipos de células respecto a su potencial regenerativo ${ }^{18}$.

Los principales desafíos de la terapia celular, independientemente del tipo de célula, siguen siendo la pobre retención del total de células y el alto grado de muerte celular después del trasplante. Por esta razón es probable que nunca se aproveche todo el potencial de la terapia celular hasta que se superen estos problemas ${ }^{18}$.

Puede decirse que somos el resultado de las células madre embrionarias humanas dentro del blastocito y estas nos mantienen jóvenes al repararnos endógenamente según las necesidades. Fueron los trabajos pioneros de Wilmut et al. y Thomson et al. acerca de la clonación y la identificación de células madre embrionarias humanas los que iniciaron una nueva era para la investigación en biología molecular de células madre que conduce al potencial terapéutico $^{19}$.

\section{Células madre pluripotentes inducidas y su uso potencial en arritmias}

El síndrome de QT largo (SQTL) ha sido uno de los primeros modelos de enfermedad basado en CMPi, en el que la prolongación del período de despolarización se asocia con mayor riesgo de arritmias ventriculares letales. Al respecto se tienen estudios basados en CMPi de las variantes genéticas LQTS1, LQTS2 y LQTS3 ${ }^{20}$.

Para el tratamiento de la disfunción del nódulo sinusal hay optimismo por investigaciones recientes sobre el uso del trasplante celular y transferencia de genes. Sin embargo, ni la transferencia génica ni el trasplante celular en esta etapa pueden recapitular la función normal de los nodos sinusales nativos, a excepción de ser un paliativo en el síndrome del seno enfermo. Por otra parte, todavía se necesita avanzar en asuntos como la transitoriedad en la expresión transgénica y la relocalización celular trasplantada. En respuesta a esta necesidad ha surgido el marcapasos cardíaco de ingeniería tisular (MCIT), el cual ha evitado efectivamente los problemas anteriores. Los MCIT como tejidos de latido espontáneo pueden fabricarse sembrando células marcapasos en andamios apropiados in vitro ${ }^{21}$.

No obstante, el desarrollo de la ingeniería tisular se ha visto retrasado por la falta de una vasculatura eficiente de los tejidos modificados. Es así como recientemente se investigó la vascularización del MCIT mediante el cocultivo con células progenitoras endoteliales (CPE) lo cual puede ayudar a resolver el cuello de botella de la ingeniería de tejidos para mejorar el suministro de oxígeno y la nutrición en todos los tejidos de ingeniería. El MCIT puede tener el potencial de actuar como marcapasos biológicos prácticos en la terapia de la arritmia o el síndrome del seno enfermo ${ }^{21}$.

Vale la pena destacar que hoy día, para la transformación biológica de células marcapaso, las células madre mesenquimales óseas parecen ser las células madre óptimas. En cuanto a la formación del nódulo sinoauricular es esencial el factor de transcripción específico para el corazón, la proteína T-Box 18 (TBX18), particularmente la formación de la zona que genera los impulsos eléctricos que inducen la contracción cardíaca situada en la cabeza nodal. Por esta razón, representa una posible alternativa terapéutica a los dispositivos electrónicos. No obstante, se debe evaluar su seguridad por medio de su aplicación a largo plazo en animales grandes antes de su uso en pacientes con disfunción sinusal ${ }^{22}$.

Los avances recientes en las técnicas de investigación relacionadas con la biología molecular, la investigación con células madre y la ingeniería de tejidos han generado nuevos métodos terapéuticos para una variedad de trastornos cardiovasculares. Adicionalmente, se están desarrollando nuevos métodos de reparación y tratamiento miocárdico de una variedad de enfermedades cardiovasculares gracias a las terapias basadas en células y genes ${ }^{23}$.

\section{Estudios de prueba de concepto}

De tiempo atrás con el propósito de mejorar la automaticidad cardiaca se vienen abordando diferentes enfoques biológicos. El objetivo común es generar una región ectópica de automaticidad en el corazón que pueda funcionar como un sustituto del nódulo sinoauricular. Para tal fin se vienen desarrollando investigaciones con enfoques basados en genes y también en células para generar marcapasos biológicos ${ }^{11}$.

\section{Estudios clínicos}

Desde el punto de vista de algunos hitos en la historia de la medicina de las células madre, la reparación de tejidos que utiliza principios de cultivo celular existe desde finales de la década de 1930 y el uso clínico de células madre derivadas de médula ósea o hematopoyéticas para el tratamiento de trastornos hematológicos existe desde fines de la década de $1950^{24}$. Sin embargo, en lo relativo a la investigación en cardiología, un paradigma en los tratamientos para la enfermedad cardiovascular se debe al punto de vista de que el corazón es un órgano terminalmente diferenciado con poca o ninguna capacidad regenerativa. Este paradigma cambió después de la identificación de una pequeña población residente de células madre cardiacas multipotentes, redefiniendo al corazón como un órgano con la capacidad de autorrenovación. Ahora se entiende que, aunque son células diferenciadas terminalmente, hay un recambio de cardiomiocitos del 1 al $2 \%$ por año en la edad adulta ${ }^{25}$.

Desde los primeros ensayos en humanos, hasta grandes ensayos clínicos multicéntricos, las lecciones de más de 200 ensayos clínicos y de alrededor de 50 metaanálisis han dado forma a la comprensión de cómo las células madre pueden mejorar la función cardíaca y han guiado la búsqueda del enfoque más eficaz. Sin embargo, a pesar de dos décadas de arduo trabajo, la transición desde la investigación a la práctica clínica todavía es controversial ${ }^{25}$. 
La terapia celular para promover la regeneración y reparación cardíaca es segura y potencialmente prometedora según la investigación actual; no obstante, hasta la fecha no se ha realizado ningún ensayo con suficiente poder estadístico para demostrar la eficacia de la terapia celular para reducir la mortalidad, pero sí se han investigado múltiples tipos de células para una variedad de afecciones cardíacas (insuficiencia cardiaca, angina refractaria, infarto agudo de miocardio, miocardiopatía isquémica crónica, cardiopatía dilatada no isquémica), y se han aprendido importantes lecciones sobre el diseño de ensayos. Esta experiencia está guiando la primera cohorte de ensayos en curso de fase III en estas enfermedades ${ }^{25}$ y actualmente se están realizando estudios clínicos en la Universidad de Johns Hopkins con células madre para el tratamiento de las arritmias cardiacas hereditarias en humanos, como se menciona en el identificador NCT02413450 en la base de datos clinicaltrials.gov.

\section{Discusión}

En los últimos diez años la terapia basada en células madre ha ganado una atención creciente, enfocada principalmente en la reparación cardíaca después de un infarto de miocardio. Una revisión de 2012, que agrupó 50 estudios que incluyeron 2.625 pacientes con cardiopatía isquémica, demostró una mejoría significativa a largo plazo en los parámetros cardíacos (fracción de eyección ventricular izquierda, tamaño del infarto, diámetro diastólico final y diámetro sistólico final) y una posible disminución de la mortalidad cardíaca en pacientes tratados con células madre derivadas de la médula ósea. Por otra parte, la terapia basada en células madre para el tratamiento de arritmias o trastornos de la conducción todavía está en sus inicios y nunca se ha probado en humanos. Varios estudios realizados in vitro y en grandes modelos animales han proporcionado pruebas de que, tanto las terapias basadas en genes, como las basadas en células, son plataformas eficaces para crear un marcapasos biológico. No obstante, ninguna de estas estrategias ha cumplido con los altos requisitos de seguridad y calidad necesarios para la traducción clínica ${ }^{17}$.

Con base en la información anterior puede decirse que si los enfoques actuales para la estimulación biológica exhiben éxito a largo plazo en modelos animales relevantes, quedan obstáculos significativos antes de que esta tecnología pueda ser ampliamente adoptada para tratar pacientes con bradicardia sintomática. Varios de estos obstáculos han sido materia de debate actual, incluido el desarrollo de mejores métodos de administración de genes y células para áreas objetivo, así como la posibilidad de efectos proarrítmicos de marcapasos biológicos y efectos no deseados u oncogénicos de terapias basadas en células madre y factores de transcripción. Además, puede haber factores genéticos que predisponen a los pacientes, especialmente a los más jóvenes, a la disfunción de las células marcapaso. En tales casos la reprogramación con las propias células del paciente podría traducirse en células marcapaso disfuncionales y resultados subóptimos.

Si bien es cierto que todas estas nuevas tecnologías lucen prometedoras, el mayor obstáculo que enfrentan será definir su nicho clínico. Los pacientes con enfermedad del sistema de conducción suelen estar bien atendidos por marcapasos electrónicos, por lo que un marcapasos biológico tendría que cumplir con un alto estándar de rendimiento para suplantar la tecnología existente.

En todo caso ya se visualizan algunas funciones clínicas importantes para la estimulación biológica. Por ejemplo, hay pacientes que requieren la eliminación de la maquinaria del marcapasos del cuerpo para someterse a un intervalo sin dispositivo, como aquellos con infecciones endovasculares activas para antibioticoterapia. Otro caso tiene que ver con los pacientes que requieren procedimientos asociados con una morbilidad significativa, como los ocasionados por marcapasos transvenosos temporales (el nivel de cuidado actual), en los que una tecnología como la reprogramación somática basada en Tbx18 podría proporcionar estimulación de respaldo temporal durante intervalos libres del dispositivo. Existe otra aplicación clínica potencial en niños con bradicardia severa que enfrentan una vida con maquinaria permanente, cambios de batería y revisiones de los cables, para quienes un marcapasos biológico autosostenible que proporcione estimulación fisiológica a largo plazo sería transformador $^{13}$. Sin olvidar que si bien los resultados de la sobreexpresión viral de Tbx18 son interesantes y altamente alentadores para el objetivo de desarrollar un marcapasos biológico, ahora hay evidencia de que podría haber riesgo de enfermedades cardíacas como resultado de la expresión ectópica de $\operatorname{Tb} \times 18^{26}$.

Los recientes avances en la reprogramación celular pueden ofrecer nuevas oportunidades para el nódulo sinoauricular inducido (NSAi) que pueden llevar a cabo dispositivos electrónicos de maneras clínicamente importantes, incluida la capacidad de acoplarse con el sistema nervioso autónomo del paciente. Así tenemos que tratar el bloqueo AV y el bloqueo infrahisiano también puede ser factible utilizando enfoques biológicos:

1. Bloqueo AV: en el futuro podrían desarrollarse células de reprogramación de la vía $\mathrm{AV}$ lenta, que tienen una entrada separada al haz de His, para aumentar la automaticidad.

2. Bloqueo infrahisiano: podría considerarse la reprogramación de miocitos ventriculares a un fenotipo de conducción rápida o estrategias para trasplantar tractos de conducción eléctrica diseñados. Las pruebas de enfoques más nuevos requerirán un diseño cuidadoso de modelos experimentales que recapitulen de cerca una fisiopatología clínica bien descrita y utilicen una terapia biológica dirigida, mínimamente invasiva y permanente $^{27}$.

Algunos ejemplos de estrategias celulares y genéticas empleadas en la regeneración cardíaca son:

a) Células madre mesenquimales (CMM): son una de las más atractivas y pueden aislarse fácilmente de diferentes tejidos, incluidos la médula ósea, la sangre periférica, el cordón umbilical y el tejido adiposo; por ejemplo, las células derivadas de tejido adiposo marrón se diferencian de las células del sistema de conducción cardiaca y son similares a las células marcapaso in vitro e in vivo ${ }^{28}$. 
Tabla 2 Requisitos mínimos de los marcapasos biológicos para ensayos clínicos

a. El constructo debe tener una expresión funcional estable durante al menos un año y no debe migrar desde el sitio de implantación.

b. No debe conferir ningún riesgo de infección / neoplasia.

c. Debe tener menor tasa de complicaciones que los dispositivos electrónicos.

d. Debe poseer capacidad de respuesta autónoma enérgica y robusta.

e. Ausencia de supresión de sobremarcha significativa.

f. Se debe implantar en un sitio ventricular previamente especificado que se selecciona de acuerdo con la etiología de la bradicardia.

g. No debe inducir arritmias.

h. Las células de bioingeniería deben ser accesibles de manera segura y fácil para la ablación con catéter.

Adaptada de: Chauveau S. ${ }^{17}$

b) Gen Shox2: su aplicación clínica en el campo de los marcapasos biológicos de seguro fomentará ideas sobre nuevos métodos terapéuticos 29,30 .

c) Otras estrategias, como células genéticamente modificadas para expresar canales $\mathrm{Na}+$, podrían ser útiles para el desarrollo de estrategias terapéuticas tanto para bradiarritmias como para taquiarritmias ${ }^{31}$.

\section{Requisitos y desafíos para su aplicación clínica}

Mientras que el marcapasos electrónico es solo un paliativo, la anhelada posibilidad de una "cura" se basa actualmente en el potencial para la expresión duradera de los genes transfectados en las células madre mesenquimales humanas y la actividad espontánea en las células madre pluripotentes diferenciadas por un linaje cardíaco. La terapia basada en genes ha sido una prueba maravillosa de principios y demostró que la manipulación genética basada en la comprensión de los fundamentos biofísicos de la actividad de los marcapasos y ha sido una estrategia eficaz para construir bloques; sin embargo, para competir con los dispositivos electrónicos, los marcapasos biológicos tendrán que cumplir estándares de seguridad y calidad más altos que los que se han logrado hasta ahora (tabla 2$)^{17}$.

Luego de revisar la literatura actual se plantean las siguientes limitaciones a manera de interrogantes, pues un desarrollo completo de esta tecnología podría revertir la patología subyacente de la enfermedad del sistema de conducción. Por ejemplo, en pacientes con disfunción incipiente del nodo sinusal, ¿sería posible entregar factores de reprogramación directamente a las áreas afectadas en el nodo sinoauricular, bloquear la pérdida de células madre relacionada con la enfermedad y restablecer la correspondencia entre el origen y el receptor? ¿Se podría rejuvenecer un nodo sinoauricular enfermo y retrasar o prevenir la necesidad de un marcapasos electrónico? Se espera que futuras investigaciones aborden estas preguntas. De superar los desafíos ya delineados esta terapia constituiría un verdadero cambio de paradigma en el tratamiento de la bradicardia $^{13,32-34}$.

\section{Conclusiones}

Han transcurrido más de veinte años desde que se realizó el primer experimento de trasplante de células para la regeneración cardíaca. Desde entonces, se han concebido y comenzado varios ensayos clínicos. Sin embargo, es difícil emitir conclusiones porque la mayoría de ensayos aún se encuentran en las fases iniciales. Los marcapasos biológicos modifican los miocitos "no marcapasos" para proporcionar automaticidad mediante tecnologías de terapia génica, o agregan sincitios de marcapasos al corazón a través de terapias con células madre adultas o embrionarias. Los marcapasos biológicos se hallan en las primeras etapas de desarrollo y los desafíos actuales incluyen dificultad para garantizar el injerto a largo plazo y el potencial de proarritmias.

\section{Financiación}

Ninguna.

\section{Conflicto de intereses}

Ninguno.

\section{Bibliografía}

1. Matsa E, Sallam K, Wu JC. Cardiac stem cell biology: Glimpse of the past, present, and future. Circ Res. 2014;114:21-7.

2. Kusumoto FM, Schoenfeld MH, Barrett C, Lee R, Edgerton JR, Marine JE, et al. 2018 ACC / AHA /HRS Guideline on the Evaluation and Management of Patients With Bradycardia and Cardiac Conduction Delay A Report of the American College of Cardiology / American Heart Association Task Force on Clinical Practice Guidelines and the Heart. 2018.

3. Vogler J, Breithardt G, Eckardt L. Bradiarritmias y bloqueos de la conducción. Rev Cardiol Esp. 2013;65:656-67.

4. Castelnuovo E, Stein K, Pitt M, Garside R, Payne E. The effectiveness and cost-effectiveness of dual-chamber pacemakers compared with single-chamber pacemakers for bradycardia due to atrioventricular block or sick sinus syndrome: systematic review and economic evaluation. Health Technol Assess (Rockv). 2005;9.

5. Lemcke H, Voronina N, Steinhoff G, David R. Recent Progress in Stem Cell Modification for Cardiac Regeneration. Stem Cells Int. 2018;2018:1-22. Disponible en: hindawi.com/journals/sci/2018/1909346/.

6. Haddad SAP, Houben RPM, Serdijin WA. The evolution of pacemakers. IEEE Eng Med Biol Mag. 2006;25:38-48. Disponible en: ieeexplore.ieee.org/document/1636350/.

7. Kar AK, Roy D, Sinha PK. Electricity and the heart. J Assoc Physicians India. 2005;53:1055-9. Disponible en: ncbi.nlm.nih.gov/pubmed/ 16572963.

8. Aquilina 0 . A brief history of cardiac pacing. Images Paediatr Cardiol. 2006;8:17-81. Disponible en: http:ncbi.nlm.nih.gov/pubmed/22368662.

9. Bestetti RB, Restini CBA, Couto LB. Development of Anatomophysiologic Knowledge regarding the Cardiovascular System: From Egyptians to Harvey. Arq Bras Cardiol. 2014. Disponible en: gnresearch.org/doi/10.5935/abc. 20140148.

10. Tjong FVY, Reddy VY. Permanent Leadless Cardiac Pacemaker Therapy. Circulation. 2017;135:1458-70. Disponible en: circ.ahajournals.org/lookup/doi/10.1161/CIRCULATIONAHA. 116.025037. 
11. Cingolani E, Goldhaber JI, Marbán E. Next-generation pacemakers: from small devices to biological pacemakers. Nat Rev Cardiol. 2017;15:139-50. Disponible en: nature.com/doifinder/10.1038/nrcardio.2017.165.

12. Van Eif VW, Devalla HD, Boink GJJ, Christoffels VM. Transcriptional regulation of the cardiac conduction system. Nat Rev Cardiol. 2018. Disponible en: nature.com/articles/s41569-018$0031-y$.

13. Vedantham V. New Approaches to Biological Pacemakers: Links to Sinoatrial Node Development. Trends Mol Med. 2015;21:749-61. Disponible en: linkinghub.elsevier.com/retrieve/pii/S1471491415001926.

14. Barbuti A, Robinson RB. Stem Cell-Derived Nodal-Like Cardiomyocytes as a Novel Pharmacologic Tool: Insights from Sinoatrial Node Development and Function. Pharmacol Rev. 2015;67:368-88. Disponible en: pharmrev.aspetjournals. org/cgi/doi/10.1124/pr.114.009597.

15. van Weerd JH, Christoffels VM. The formation and function of the cardiac conduction system. Development. 2016;143:197-210. Disponible en: dev.biologists.org/ lookup/doi/10.1242/dev.124883.

16. Herreros J, Chachques JC, Trainini J, Pontón A, Sarralde A, Genovese J. Regeneración celular cardíaca. Cirugía Cardiovasc. 2011;18:207-15. Disponible en:linkinghub.elsevier.com/ retrieve/pii/S1134009611700560.

17. Chauveau S, Brink PR, Cohen IS. Stem cell-based biological pacemakers from proof of principle to therapy: a review. Cytotherapy. 2014;16:873-80. Disponible en: linkinghub.elsevier.com/retrieve/pii/S146532491400512X.

18. Cambria E, Pasqualini FS, Wolint P, Günter J, Steiger J, Bopp A, et al. Translational cardiac stem cell therapy: advancing from first-generation to next-generation cell types. NPJ Regen Med. 2017;2:17. Disponible en: nature.com/articles/s41536017-0024-1.

19. Ahmad H, Hashmi S. Is biological repair of Heart on the Horizon? Pakistan J Med Sci. 2017;33(4.).

20. Yoshida Y, Yamanaka S. Induced Pluripotent Stem Cells 10 Years Later. Circ Res. 2017;120:1958-68.

21. Zhang L, Li X, Yu X, Li Y, Sun A, Huang $C$, et al. Construction of vascularized pacemaker tissues by seeding cardiac progenitor cells and endothelial progenitor cells into Matrigel. Life Sci. 2017;179:139-46. Disponible en: linkinghub.elsevier.com/retrieve/pii/S0024320517302254.

22. Li Y, Yang M, Zhang G, Li L, Ye B, Huang C, et al. Transcription factor TBX18 promotes adult rat bone mesenchymal stem cell differentiation to biological pacemaker cells. Int J Mol Med. 2018;41:845-51. Disponible en: ncbi.nlm.nih.gov/pubmed/29207072.

23. Pokushalov E, Romanov A, Steinberg JS. Stem Cell Therapy for Electrophysiological Disorders. Curr Cardiol Rep. 2013;15:408. Disponible en: link.springer.com/10.1007/s11886-013-0408-9.

24. Ratcliffe E, Glen KE, Naing MW, Williams DJ. Current status and perspectives on stem cell-based therapies undergoing clinical trials for regenerative medicine: case studies. $\mathrm{Br}$ Med Bull. 2013;108:73-94. Disponible en: academic.oup.com/bmb/ article-lookup/doi/10.1093/bmb/ldt034.

25. Banerjee MN, Bolli R, Hare JM. Clinical Studies of Cell Therapy in Cardiovascular Medicine. Circ Res. 2018;123:266-87. Disponible en: circres.ahajournals.org/lookup/doi/10.1161/ CIRCRESAHA.118.311217.

26. Brand T. Tbx18 and the generation of a biological pacemaker Are we there yet? J Mol Cell Cardiol. 2016;97:263-5.

27. Meyers JD, Jay PY, Rentschler S. Reprogramming the conduction system: Onward toward a biological pacemaker. Trends Cardiovasc Med. 2016;26:14-20. Disponible en: linkinghub.elsevier.com/retrieve/pii/S1050173815001127.

28. Takahashi T, Nagai T, Kanda M, Liu M-L, Kondo N, Naito AT, et al. Regeneration of the Cardiac Conduction System by Adipose Tissue-Derived Stem Cells. Circ J. 2015;79:2703-12. Disponible en: jstage.jst.go.jp/article/circj/79/12/79_CJ-150400/_article.

29. Hu W, Xin Y, Zhao Y, Hu J. Shox2: The Role in Differentiation and Development of Cardiac Conduction System. Tohoku J Exp Med. 2018;244:177-86. Disponible en: jstage.jst.go.jp/article/tjem/244/3/244_177/_article.

30. Schmitteckert S, Griesbeck A, Sumer S, Jauch A, Rolletschek A, Niesler B, et al. Murine transgenic embryonic stem cell lines for the investigation of sinoatrial node-related molecular pathways. Stem Cell Res. 2017;25:278-82. Disponible en: linkinghub.elsevier.com/retrieve/pii/S1873506117301356.

31. Hofshi A, Itzhaki I, Gepstein A, Arbel G, Gross GJ, Gepstein L. A combined gene and cell therapy approach for restoration of conduction. Hear Rhythm. 2011;8:121-30.

32. Marelli D, Desrosiers C, El-Alfy M, Kao R, Chiu CR. Cell transplantation for myocardial repair: an experimental approach. Cell Transplant. 1992;1:383-90.

33. Leier M. Advancements in Pacemaker Technology: The Leadless Device. Crit Care Nurse. 2017;37:58-65.

34. Madhavan M, Mulpuru SK, McLeod CJ, Cha Y-M, Friedman PA. Advances and Future Directions in Cardiac Pacemakers. J Am Coll Cardiol [Internet]. 2017;69:211-35. 